\title{
Aproveitamento de resíduos da agroindústria do óleo de dendê para a produção de lipase por Aspergillus niger
}

\author{
Agro-industrial residues utilization of palm oil for lipase production by Aspergillus niger
}

\author{
Edmar das Mercês Penha ${ }^{\mathrm{I}^{*}}$ Ludmila de Araújo Nunes Viana $^{\mathrm{II}}$ Leda Maria Fortes Gottschalk \\ Selma da Costa Terzi ${ }^{I}$ Erika Fraga de Souza ${ }^{I}$ Sidinéa Cordeiro de Freitas ${ }^{I}$ \\ Juliana de Oliveira Santos ${ }^{\mathrm{I}}$ Thaís Fabiana Chan Salum ${ }^{\mathrm{III}}$
}

\section{RESUMO}

Neste trabalho, foi avaliado o desempenho de duas linhagens de Aspergillus niger (mutante 11 T53A14 e selvagem C) previamente selecionadas como promissoras para a produção de lipases, utilizando meios de cultivo formulados a partir da torta de dendê (palmiste) e da borra alcalina do refino do óleo de dendê (borra de dendê), resíduos provenientes da agroindústria do óleo de dendê (palma) por fermentação em estado sólido (FES). Os experimentos de produção da enzima em FES foram conduzidos em colunas aeradas, incubadas em banho-maria a $32^{\circ} \mathrm{C} \mathrm{com}$ entrada controlada de ar não umedecido de 1,0vvm. Os melhores resultados foram obtidos com a cepa mutante A. niger 11 T53A14 em meio contendo torta de dendê umedecida com solução sulfato de amônio $(1,2 \%)$ e com a adição de $3 \%$ da borra de dendê. $O$ valor máximo da atividade da lipase neste meio foi de $72,57 \mathrm{U}_{\mathrm{ss}}{ }^{-1} \mathrm{em} 48$ horas. Esse valor foi $47,5 \%$ superior ao obtido no meio sem a borra de dendê. A comparação do desempenho da cepa mutante com a cepa selvagem mostrou que o meio composto por torta de dendê adicionado com sulfato de amônio e borra de dendê induziu ambas as linhagens a produzir lipases com bons níveis de atividade, além de reduzir o tempo de processo de fermentação.

Palavras-chave: lipase, resíduo agroindustrial, Aspergillus niger.

\section{ABSTRACT}

In this paper it was evaluated the performance of two strains of Aspergillus niger (mutant 11T53A14 and wild type C) previously selected as promising for lipase production, from cultivation media formulated from palm kernel cake (kernel) and alkaline sludge from refining were evaluated palm oil (palm oil sludge), palm oil (palm) waste industrialization by solid state fermentation (SSF). Experiments of enzyme production in SSF were conducted in aerated columns, incubated in a water bath at $32^{\circ} \mathrm{C}$ with controlled inlet of $1.0 \mathrm{vvm}$. The best results were obtained with the mutant strain A. niger 11 T53A14 in medium containing palm kernel cake moistened with a solution of ammonium sulfate (1.2\%) and with the addition of $3 \%$ of palm oil sludge. The maximum lipase activity in this medium was $72.57 \mathrm{U} \mathrm{g}_{d w}^{-1}$ in 48 hours and $47.5 \%$ higher than in the medium without sludge palm. A comparison of the performance of the mutant strain with the wildtype strain showed that the medium composed of palm kernel cake added with ammonium sulfate and blurs palm induced both strains to produce lipases with good activity levels and reduced the time of the fermentation process.

Key words: lipase, agro-industrial residue, Aspergillus niger.

\section{INTRODUÇÃO}

Enzimas são proteínas com atividade catalítica que possibilitam inúmeras reações químicas em condições muito suaves, comparativamente aos processos químicos tradicionais. As lipases são empregadas em mais de $20 \%$ das biotransformações de síntese orgânica (JAYAPRAKASH \& EBENEZER, 2010). Essas enzimas podem ser usadas para catalisar a síntese de ésteres de ácidos carboxílicos, componentes importantes de aromas naturais empregados na indústria alimentícia, que contribuem na formação e acentuação dos aromas em alimentos ou em catalisar a hidrólise de triacilgliceróis aos ácidos graxos correspondentes e glicerol, como na produção de biodiesel por esterificação de óleos vegetais (JAEGER et al., 1993;

\footnotetext{
'Laboratório de Processos Fermentativos, Embrapa Agroindústria de Alimentos, Av. das Américas, 29501, 23020-470, Rio de Janeiro, RJ, Brasil. E-mail: edmar.penha@embrapa.br. *Autor para correspondência.

${ }^{\text {II } C e n t r o ~ U n i v e r s i t a ́ r i o ~ E s t a d u a l ~ d a ~ Z o n a ~ O e s t e ~(U E Z O), ~ R i o ~ d e ~ J a n e i r o, ~ R J, ~ B r a s i l . ~}$

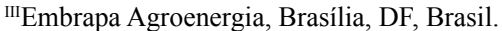


MACEDO \& PASTORE, 1997; FERNANDES, 2007). As lipases podem atuar tanto em meio aquoso quanto em meio orgânico, com teor de água restrito, e são consideradas carboxilesterases que atuam em substratos emulsificados (CASTRO et al., 2004).

A popularização do uso de enzimas, que esbarra no elevado custo das enzimas comerciais, e depende da escolha de micro-organismos mais eficientes, de meios de cultivos mais baratos ou de processos fermentativos mais adequados que, dessa forma, possibilitem aumentar a produtividade e o rendimento, reduzindo custos e ampliando a produção (SANTOS, 2014).

As linhagens de Aspergillus niger tem se mostrado mais promissoras para produzir lipase extracelular, o que facilita a recuperação da enzima (AGUIAR \& MENEZES, 2000; MESSIAS et al., 2011).

Aprodução de enzimas de baixo custo passa, também, pela utilização de resíduos agroindustriais, como suporte e substrato para o agente fermentativo. Diferentes combinações de resíduos agroindustriais têm sido testadas para a produção de lipase, como torta de babaçu com óleo de oliva (CASTILHO et al., 2000) e óleo de mamona com farelo de trigo (DUTRA et al., 2008). O resíduo resultante da extração do óleo da amêndoa do dendê ou palmiste (torta de dendê), usada quase que na sua totalidade na alimentação animal, possui alto conteúdo de fibra, teor de proteína bruta de $14 \%$ a $15 \%, 3 \%$ a $5 \%$ de óleo residual, cerca de $11 \%$ de água, $48 \%$ de carboidratos e $4 \%$ de cinzas (FURLAN JÚNIOR, 2006).

Ainda vinculada à indústria do óleo de dendê, a borra alcalina, subproduto do refino de óleos comestíveis durante a etapa de neutralização alcalina do óleo, representa um grande problema ambiental. Ela consiste de uma mistura de sabão, óleo arrastado, substâncias insaponificáveis, gomas, fosfatídeos, pigmentos, água e ácidos graxos (MURUCI, 2012).

Neste trabalho, objetivou-se avaliar o desempenho de duas linhagens de Aspergillus niger para a produção de lipases por fermentação em estado sólido (FES). Os meios de cultivo foram formulados a partir da torta de dendê (palmiste) e da borra alcalina do refino do óleo de dendê (borra de dendê), resíduos da agroindústria do óleo de dendê.

\section{MATERIAL E MÉTODOS}

Manutenção e ativação dos micro-organismos

Os agentes da fermentação foram os fungos filamentosos Aspergillus niger 11T53A14 (mutante obtido por técnica convencional de exposição a agente mutagênico) e Aspergillus niger C (selvagem), pertencentes à Coleção de Culturas da Embrapa Agroindústria de Alimentos e bons produtores de lipase (MURUCI et al., 2012; SANTOS et al., 2014). As linhagens foram mantidas e ativadas em meio básico, em gelose inclinada, tendo como fonte de carbono o óleo de oliva e contendo os seguintes elementos $\left(\mathrm{g} \mathrm{L}^{-1}\right)$ : nitrato de sódio $(3,0)$, sulfato de magnésio $(0,5)$, cloreto de potássio $(0,5)$, sulfato ferroso $(0,01)$, fosfato dibásico de potássio $(1,0)$, agar-agar $(30,0)$ e azeite de oliva $\left(20,0 \mathrm{~mL} \mathrm{~L}^{-1}\right)$ (COURI \& FARIAS, 1995).

\section{Produção dos esporos}

Após indução na gelose com óleo de oliva, foram adicionados $20 \mathrm{~mL}$ de solução aquosa $0,3 \%$ de Tween 80 sobre os conídios da gelose inclinada para, assim, obter uma suspensão de esporos. Um mililitro dessa suspensão foi transferido para o meio de sabugo de milho moído (COURI \& FARIAS, 1995). Esse meio foi preparado a partir do sabugo de espigas de milho . O sabugo foi seco a $100^{\circ} \mathrm{C}$ em estufa com aeração por 4 horas e moído em moinho de facas (granulometria de 3-4mm). Para preparação do meio sólido de produção de esporos, são adicionados, por grama de sabugo de milho, $1,3 \mathrm{~mL}$ de uma solução com nutrientes contendo peptona $\left(56,0 \mathrm{~g} \mathrm{~L}^{-1}\right)$, fosfato de potássio monobásico $\left(0,76 \mathrm{~g} \mathrm{~L}^{-1}\right)$, sulfato de zinco $\left(19,8 \mathrm{mg} \mathrm{L}^{-1}\right)$, sulfato de ferro $\left(23,0 \mathrm{mg} \mathrm{L}^{-1}\right)$ e sulfato de manganês $\left(0,05 \mathrm{mg} \mathrm{L}^{-1}\right)$. Os frascos cônicos de $125 \mathrm{~mL}$ com $4,6 \mathrm{~g}$ do meio de sabugo foram autoclavados a $1 \mathrm{~atm}$ por uma hora e, após resfriamento e inoculação dos esporos, foram incubados por cinco dias a $32^{\circ} \mathrm{C}$. Os frascos contendo os esporos foram mantidos por até um mês a $4^{\circ} \mathrm{C}$.

Preparo do inóculo para a produção de lipase

Para o preparo do inóculo, foram adicionados $20 \mathrm{~mL}$ de uma solução aquosa, $0,3 \%$ de Tween 80 por frasco de meio de sabugo de milho contendo os esporos. Após filtração com gaze, a concentração de esporos foi determinada por contagem em Câmara de Neubauer. O inóculo foi padronizado em $10^{6}$ esporos por grama de meio de fermentação.

\section{Matérias-primas}

A torta e a borra de dendê, foram fornecidas pela Indústria de Extração da Amazônia, localizada em Belém (PA). Ambos os resíduos foram transportados congelados e armazenados em freezer. Para verificar a necessidade de se adicionar substâncias complementares na formulação dos meios. foram determinadas a composição centesimal e o teor de umidade, de acordo com AOAC (2011). 
Pré-tratamento da torta de dendê

A torta de dendê foi seca em estufa a $60^{\circ} \mathrm{C}$ por 8 horas, para melhor conservação durante a armazenagem. Após secagem, a torta foi triturada em moinho de facas para padronização das partículas sólidas na granulometria de $6 \mathrm{~mm}$.

Preparo dos meios para fermentação em estado sólido

O meio para fermentação foi composto por $100 \mathrm{~g}$ de torta de dendê (massa seca), umidificada com $80 \mathrm{~mL}$ de solução salina $(\mathrm{NaCl} 0,85 \%), \mathrm{pH} \mathrm{7,0,} \mathrm{ou}$ $80 \mathrm{~mL}$ de solução de sulfato de amônio $(1,2 \% \mathrm{p} / \mathrm{v}), \mathrm{pH}$ 7,0 , e adicionado ou não de indutores (borra alcalina) na concentração de $3 \%(\mathrm{p} / \mathrm{p})$, de acordo com resultados obtidos por MURUCI et al. (2012). A seguir, 40g do meio foram colocados em frasco Erlenmeyer para esterilização a $121^{\circ} \mathrm{C}$, a 1 atm por $15 \mathrm{~min}$.

Determinação da umidade do meio de fermentação

A umidade das amostras foi realizada antes da fermentação e com o meio inoculado. A análise foi determinada por gravimetria, por secagem em estufa a $100^{\circ} \mathrm{C}$ até peso constante.

Produção de lipase por fermentação em estado sólido

Os experimentos de produção da enzima foram conduzidos em colunas aeradas, incubadas em banho-maria a $32^{\circ} \mathrm{C}$ e alimentada com $1,0 \mathrm{vvm}$ (volume de ar por volume de meio por minuto) de ar, baseado nos experimentos de MACEDO et al. (2009), que também estudaram a produção de lipase por $\boldsymbol{A}$. niger em borra de milho e farelo de trigo por FES. Cada coluna recebeu $40 \mathrm{~g}$ de meio de fermentação. Na primeira etapa, Aspergillus niger 11T53A14 foi inoculado no meio de cultivo contendo como substrato a torta de dendê em três diferentes condições: umidificada com solução salina; umidificada com solução de sulfato de amônio; e umidificada com solução de sulfato de amônio e 3\% de indutor (borra alcalina de dendê). $\mathrm{Na}$ segunda etapa, Aspergillus niger 11T53A14 ou Aspergillus niger $\mathrm{C}$ foram inoculados no meio otimizado com torta de dendê umidificada, com $80 \mathrm{~mL}$ de solução de sulfato de amônio e com adição de $3 \%$ de borra de dendê como indutor. Os processos foram conduzidos por 96 horas e os valores expressos representam a média de dois experimentos em duplicatas.

As análises estatísticas foram realizadas utilizando-se o programa STATISTICA 12 da StatSoft, Inc. Na comparação das médias dos tratamentos, usou-se o teste de Fisher LSD, ao nível de probabilidade de $5 \%$.
As variáveis de processo estudadas para a produção de lipase foram: necessidade de adição de sulfato de amônio (80mL por 100 gramas de meio); necessidade de adição de $3 \%$ de indutor (3g de borra de óleo de dendê por $100 \mathrm{~g}$ de meio).

A enzima foi extraída com a adição de $2,5 \mathrm{~mL}$ de tampão fosfato de sódio $(\mathrm{pH} 7,0)$ por grama de meio fermentado, permanecendo por 1 hora sob agitação de 90 oscilações por minuto em shaker, com banho a $32^{\circ} \mathrm{C}$ (Thermo Scientific Precision Reciprocal Shaking Water Bath 50). O extrato enzimático bruto foi filtrado em papel de filtro e depois em membrana de microfiltração $(0,45 \mu \mathrm{m})$, para posterior determinação do teor de proteína total (LOWRY et al., 1951) e da atividade lipásica.

Determinação de atividade lipásica

A determinação da atividade lipásica no extrato bruto foi realizada por método titulométrico, segundo o procedimento descrito por PEREIRA et al. (2001), com pequenas modificações: adicionouse $1 \mathrm{~mL}$ do extrato enzimático a $4 \mathrm{~mL}$ de tampão citrato de sódio $50 \mathrm{mM}$ pH 4,0 e $5 \mathrm{~mL}$ de emulsão de goma arábica (48mL de água destilada, $48 \mathrm{~mL}$ de óleo de oliva e $7 \mathrm{~g}$ de goma arábica). Após $15 \mathrm{~min}$ a $35^{\circ} \mathrm{C}$, a reação foi interrompida com a adição de 10mL de uma solução 1:1:1 de acetona/etanol/ água e a titulação realizada com $\mathrm{NaOH}(0,05 \mathrm{~N})$, até $\mathrm{pH}$ final 11,0, e o resultado foi expresso em $\mathrm{U}$ por grama de substrato seco $\left(\mathrm{U} \mathrm{g}_{\mathrm{ss}}{ }^{-1}\right)$. $\mathrm{O}$ branco da reação foi realizado adicionando-se a enzima no momento da titulação. Uma unidade de atividade lipásica foi definida como a quantidade de enzima que produz $1 \mu \mathrm{mol}$ de ácidos graxos (oleico) por minuto, sob as condições de ensaio padrão. Toda a análise foi feita em duplicata para os brancos e em triplicata para as amostras.

\section{RESULTADOS E DISCUSSÃO}

Caracterização da torta e da borra de dendê

A análise centesimal da torta de dendê

(Tabela 1) mostrou haver uma boa quantidade de

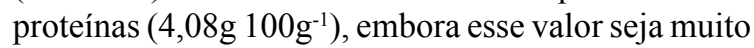
inferior àquele encontrado no farelo de trigo $(13,8 \mathrm{~g}$ $\left.100 \mathrm{~g}^{-1}\right)$ por SILVEIRA \& BADIALE-FURLONG (2007), um resíduo bastante recomendado como substrato para o desenvolvimento de fungos, visando à produção de lipases (KUMAR et al., 2011; REHMAN et al., 2011; TOSCANO et al., 2013; DAYANANDAN et al., 2013). O teor de lipídeos na

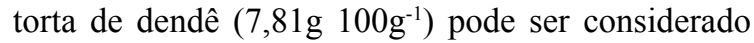
satisfatório para promover a indução e a síntese de 
Tabela 1 - Composição centesimal da torta e da borra de dendê e do farelo de trigo.

\begin{tabular}{llll}
\hline $\begin{array}{l}\text { Determinação } \\
\left(\mathrm{g} 100 \mathrm{~g}^{-1}\right)\end{array}$ & $\begin{array}{c}\text { Torta de } \\
\text { dendê }\end{array}$ & $\begin{array}{c}\text { Borra de } \\
\text { dendê }\end{array}$ & $\begin{array}{c}\text { Farelo de } \\
\text { trigo }^{* 1}\end{array}$ \\
\hline Carboidratos totais & 58,78 & 1,45 & 60,1 \\
Proteínas & 4,08 & $\mathrm{ND}^{* 2}$ & 13,8 \\
Extrato Etéreo & 7,81 & 97,86 & 5,2 \\
Cinzas & 3,99 & 0,003 & 6,3 \\
Umidade & 25,34 & 0,69 & 9,4 \\
\hline
\end{tabular}

${ }^{* 1}$ Valores obtidos de SILVEIRA \& BADIALE-FURLONG (2007).

${ }^{* 2} \mathrm{ND}$ - abaixo do limite de detecção.

lipases, pois se mostrou superior ao valor encontrado no farelo de trigo por SCHUBER et al. (2012). Estudos anteriores utilizando a cepa Aspergillus niger $\mathrm{C}$ mostraram que o farelo de trigo já possuía um teor de lipídeos suficiente para produção de lipases e que a adição de diferentes borras, como de girassol, de milho e de canola, não aumentou a produção da enzima (MURICI et al., 2012). A borra de dendê testada como indutor apresentou em sua composição
97,86\% de lipídeos, valor semelhante ao reportado por SANTOS et al., 2014.

Avaliação do uso da torta de dendê como suporte e substrato para a produção de lipase por Aspergillus niger 11T53A14

Os resultados apresentados na figura 1 mostram que o meio contendo exclusivamente torta de dendê umedecida com solução salina e $60 \%$ de umidade, conduziu a uma baixa produção de lipase por $A$. niger $11 \mathrm{~T} 53 \mathrm{~A} 14$ em $72 \mathrm{~h} \quad\left(10,64 \mathrm{U} \mathrm{g}_{\mathrm{ss}}{ }^{-1}\right)$, seguida de uma redução para $2,45 \mathrm{U} \mathrm{g}_{\mathrm{ss}}{ }^{-1}$, em 96 horas. $\mathrm{Na}$ mesma figura, observa-se que a complementação da torta de dendê com sulfato de amônio $(1,2 \%)$ aumentou a máxima atividade enzimática produzida em 4,6 vezes, elevando-a para 49,19 $\mathrm{U} \mathrm{g}_{\mathrm{ss}}{ }^{-1}$, além de reduzir o tempo de processo de 72 para 48 horas, também seguido de uma redução para $33,61 \mathrm{U} \mathrm{g}_{\mathrm{ss}}{ }^{-1} \mathrm{em}$ 72 horas. Esse declínio pode ser devido ao término do indutor presente ou dos lipídeos presente na torta de dendê. A presença de proteases no extrato enzimático produzido por fungos também pode influenciar na perda de atividade enzimática (AZEREDO et al., 2001) e CASTRO (2006).

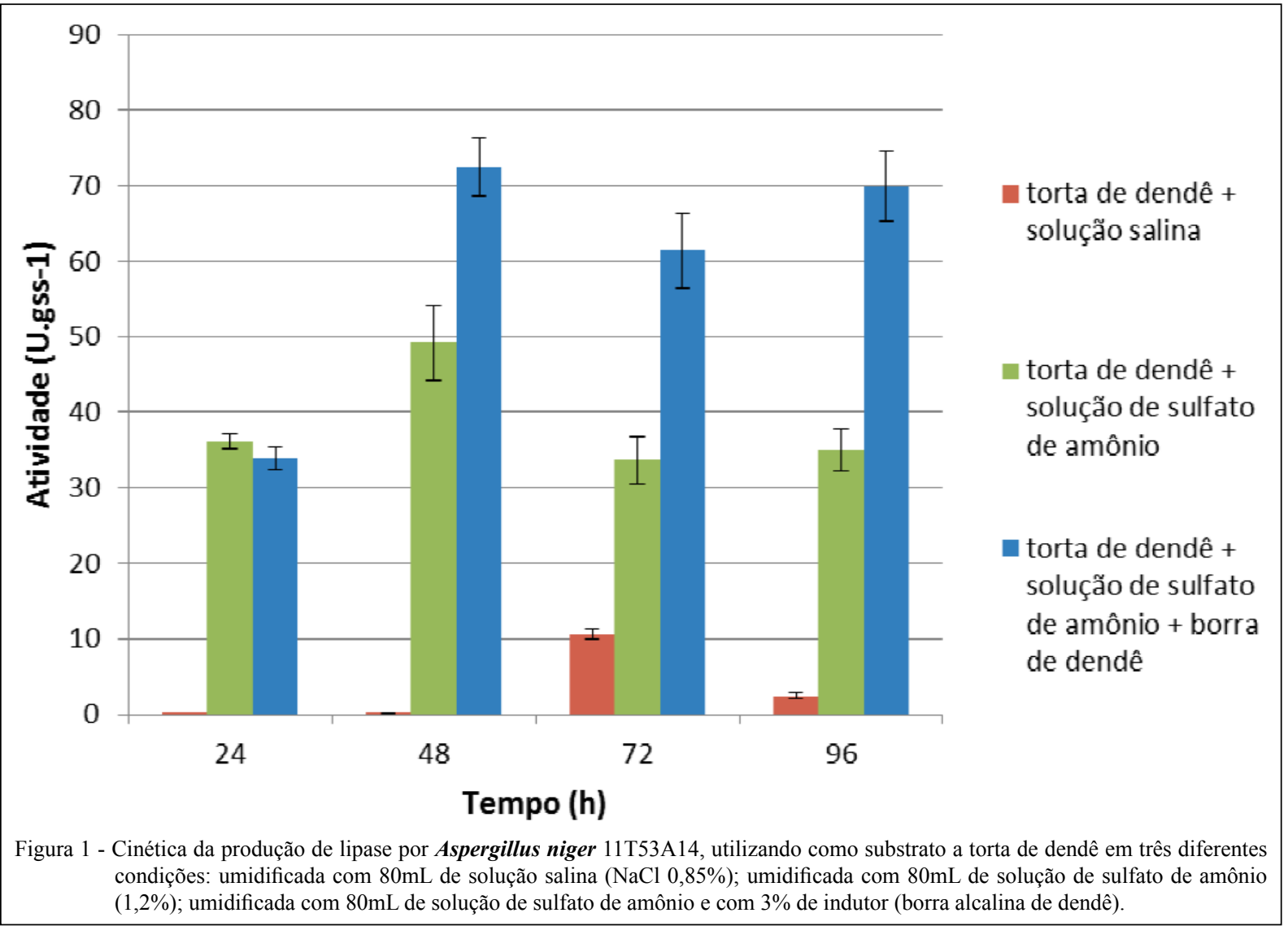

Ciência Rural, v.46, n.4, abr, 2016. 
O aumento da produção da lipase mostrou a importância da suplementação de uma fonte de nitrogênio à torta de dendê. Esses resultados estão de acordo com os obtidos por PALMA et al. (2000), em que a maior atividade lipásica $\left(27,8 \mathrm{U} \mathrm{g}_{\mathrm{ss}}{ }^{-1}\right)$ produzida por Penicillium restrictum, em FES, foi obtida quando a torta de babaçu foi enriquecida com peptona. MURUCI (2012) obteve valores expressivos em meio com farelo de trigo $\left(201,81 \mathrm{U} \mathrm{g}_{\mathrm{ss}}{ }^{-1} \mathrm{em} 72\right.$ horas), substrato que contém considerável teor de proteínas, quando comparado a outras fontes. A escolha de uma fonte de nitrogênio adequada é um fator importante ao processo de fermentação industrial, pois tem um grande impacto sobre os custos e também pode afetar seletivamente o crescimento celular e a formação de produto, em resposta às medidas bioquímicas básicas relacionadas com a sua utilização por parte da célula (GOTTSCHALK et al., 2013). A complementação da torta de dendê com sulfato de amônio utilizada nesse trabalho, aumentou a máxima atividade enzimática e reduziu o tempo de processo, melhorando a produtividade.

Os experimentos realizados com o objetivo de avaliar a influência da adição de uma fonte lipídica (borra de dendê) como indutor da produção de lipases por $\boldsymbol{A}$. niger 11 T53A14, quando cultivado em meio contendo torta de dendê umedecida com solução sulfato de amônio (1,2\%) na proporção 1:0,8, permitiram observar que a adição de $3 \%$ de borra de dendê aumentou consideravelmente a atividade enzimática (Figura 1). O valor máximo atingido de $72,57 \mathrm{U}_{\mathrm{gss}}{ }^{-1}$ em 48 horas foi $47,5 \%$ maior do que aquele obtido no meio sem indutor $\left(49,19 \mathrm{U} \mathrm{g}_{\mathrm{ss}}{ }^{-1} \mathrm{em}\right.$ 48h). Nesse caso, não foi observada uma redução da atividade, que se manteve num platô, devido à presença do indutor e de uma maior concentração de lipídeos nesse meio. Esses resultados corroboram os resultados obtidos em trabalhos anteriores, em que a produção de lipase por $\boldsymbol{A}$. niger 11T53A14 em FES, com farelo de trigo como substrato, na presença de $3,0 \%$ de borra de girassol $\left(201,8 \mathrm{U} \mathrm{g}_{\mathrm{ss}}{ }^{-1}\right)$, foi maior do que na ausência de indutor $\left(182,35 \mathrm{U} \mathrm{g}_{\mathrm{ss}}{ }^{-1}\right.$ ) (SANTOS et al., 2014). MALA et al. (2007) também estudaram diferentes combinações de indutores para a produção de lipases de $\boldsymbol{A}$. niger em FES. Segundo os autores, o farelo de trigo adicionado da torta do óleo de gergelim na proporção $3: 1$, possibilitou a obtenção de atividade lipásica de $384 \mathrm{U} \mathrm{g}_{\mathrm{ss}}{ }^{-1}$.

Apesar dos resultados inferiores aos encontrados com o farelo de trigo, a torta de dendê demonstra ser um substrato promissor, considerandose haver, ainda, a possibilidade da melhoria do processo de produção. Como a borra é um resíduo do refino de óleos, pode haver a presença de inibidores/ contaminantes neste material, que, em concentrações elevadas, podem inibir a síntese da enzima. Além disso, grandes quantidades de borra podem dificultar a transferência de massa no meio, um dos principais problemas encontrados para a FES. A análise estatística dos resultados desse bloco de ensaios mostrou haver diferenças significativas $(\mathrm{P}<0,05)$ entre os valores comparados.

A comparação da produção da lipase por uma cepa mutante Aspergillus niger 11T53A14 e por uma selvagem Aspergillus niger C foi também avaliada nas condições otimizadas (meio torta de dendê umidificado com $80 \%$ solução de sulfato de amônio e adicionado de $3 \%$ de borra de dendê). Os resultados estão na figura 2 .

Os resultados mostraram que $\boldsymbol{A}$. niger $11 \mathrm{~T} 53 \mathrm{~A} 14$ atingiu valor máximo $\left(72,57 \mathrm{U} \mathrm{g}_{\mathrm{ss}}{ }^{-1} \mathrm{em}\right.$ $48 \mathrm{~h})$ muito próximo ao de $\boldsymbol{A}$. niger $\mathrm{C}\left(67,49 \mathrm{U} \mathrm{g}_{\mathrm{ss}}{ }^{-1}\right)$. Os valores máximos da concentração de proteína extracelular obtidos foram semelhantes para os dois fungos avaliados, $6,3 \mathrm{~g} \mathrm{~L}^{-1}$ e $6,5 \mathrm{~g} \mathrm{~L}^{-1}$ para o $\boldsymbol{A}$. niger $11 \mathrm{~T} 53 \mathrm{~A} 14$ e o $\boldsymbol{A}$. niger $\mathrm{C}$, respectivamente. Embora não haja diferença significativa entre os valores da atividade enzimática $(\mathrm{P}<0,05)$, o tempo de fermentação para alcançá-lo foi consideravelmente maior (72-96h). Portanto, a linhagem $\boldsymbol{A}$. niger 11T53A14 mostrou-se mais produtiva por ter produzido, em 48 horas, a atividade máxima que a linhagem $\boldsymbol{A}$. niger $\mathrm{C}$ atingiu somente após 72 de processo.

\section{CONCLUSÃO}

A torta de dendê pura mostrou ser um substrato incompleto para a produção de lipase por A. niger 11T53A14, necessitando ser suplementado com fonte de nitrogênio pela adição de solução de sulfato de amônio.

A adição de $3 \%$ de borra de dendê ao meio de fermentação a base de torta de dendê com sulfato de amônio mostrou influenciar positivamente a produção de lipase por $\boldsymbol{A}$. niger 11T53A14, uma vez que foi capaz de aumentar a máxima atividade em $47,5 \%$.

A comparação do desempenho de $\boldsymbol{A}$. niger 11T53A14 (mutante) com uma cepa selvagem ( $\boldsymbol{A}$. niger $\mathrm{C}$ ) mostrou que o meio composto por torta de dendê adicionado de sulfato de amônio e borra de dendê induziu ambas as linhagens a produzir lipases com bons níveis de atividade, além de reduzir o tempo de processo de fermentação de 72 para 48 horas, quando foi utilizada a cepa mutante. 


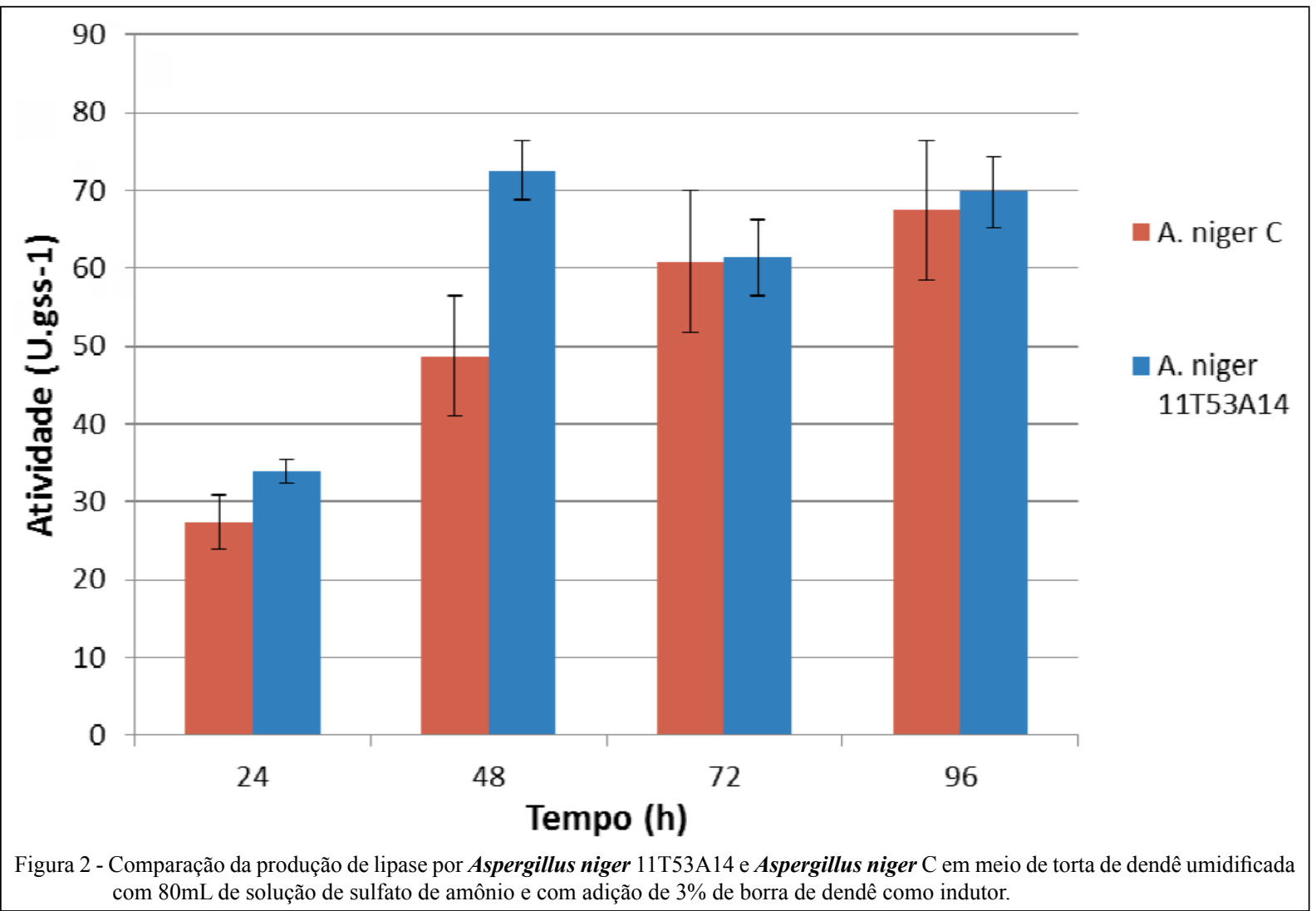

Portanto, os resultados mostraram ser possível aproveitar os resíduos do processo de fabricação do óleo de dendê (torta e borra) para a produção de lipase por Aspergillus niger 11T53A14 e, consequentemente, contribuir para reduzir seu custo de obtenção.

\section{REFERÊNCIAS}

AGUIAR, C. L.; MENEZES, T. J. B. Produção de celulases e xilanases por Aspergillus niger IZ-9 usando fermentação submersa sobre bagaço de cana-de-açúcar. Boletim do Centro de Pesquisa de Processamento de Alimentos, v. 18, n. 1, p. 57-70, 2000.

AOAC (ASSOCIATION OF OFFICIAL ANALYTICAL CHEMISTS). Official methods of analysis international. $18^{\text {th }}$ ed. $4^{\text {th }}$ rev. Gaithersburg: AOAC International, 2011.

AZEREDO, L. A. I. et al. Proteases from actinomycetes interfere in solid media plate assays of hialuronidase activity. Journal of Microbiological Methods, v. 45, n. 3, p. 207-212, 2001.

CASTILHO, L. R. et al. Economic analysis of lipase production by Penicillium restrictum in solid-state and submerged fermentations. Biochemical Engineering Journal, v. 4, p. 239-247, 2000.

CASTRO, A. M. Produção e propriedades de celulases de fungos filamentosos, obtidas a partir de bagaço de cana-deaçúcar (Saccharum spp.). 2006. 212 f. Dissertação (Mestrado em
Tecnologia de Processos Químicos e Bioquímicos) - Universidade Federal do Rio de Janeiro, Rio de Janeiro, RJ.

CASTRO, H. F. et al. Modificação de óleos e gorduras por biotransformação. Química Nova, v. 27, n. 1, p. 146-156, 2004.

COURI, S.; FARIAS, A. X. Genetic manipulation of Aspergillus niger for increased synthesis of pectinolytic enzymes. Reviews of Microbiology, v. 26, n. 4, p. 314-317, 1995.

DAYANANDAN, A. et al. Enhanced production of Aspergillus tamarii lipase for recovery of fat from tannery fleshings. Brazilian Journal of Microbiology, v. 44, n. 4, p. 1089-1095, 2013.

DUTRA, J. C. V. et al. Lipase production in solid-state fermentation monitoring biomass growth of $\mathrm{A}$. niger using digital image processing. Applied Biochemistry and Biotechnology, n. 147 , p. $63-75,2008$.

FERNANDES, M. L. M. et al. Esterification and transesterification reactions catalysed by addition of fermented solids to organic reaction media. Journal of Molecular Catalysis B: Enzymatic, v. 44 , p. $8-13,2007$.

GOTTSCHALK, L. M. F. et al. Efficient production of lignocellulolytic enzymes xylanase, $\beta$-xylosidase, ferulic acid esterase and $\beta$-glucosidase by the mutant strain Aspergillus awamori $2 \mathrm{~B} .361$ U2/1. Brazilian Journal of Microbiology, v. 44, p. 569-576, 2013.

JAEGER, K. E. et al. Topological characterization and modeling of the 3D structure of lipase from Pseudomonas aeruginosa.

Ciência Rural, v.46, n.4, abr, 2016. 
Federation of European Biochemical Societies, v. 332, n. 1/2, p. 143-149, 1993.

JAYAPRAKASH, A.; EBENEZER, P. Investigation on extracellular lipase production by Aspergillus japonicus isolated from the paper nest of Ropalidia marginata. Indian Journal of Science and Technology, v. 3, n. 2, p. 113-117, 2010.

KUMAR, S. et al. Use of evolutionary operation (EVOP) factorial design technique to develop a bioprocess using grease waste as a substrate for lipase production. Bioresource Technology, v. 02, n. 7, p. 4909-4912, 2011

LOWRY, O. H. et al. Protein measurement with the Folin phenol reagent. Journal of Biological Chemistry, v. 193, p. 265-275, 1951.

MACEDO, L. N. M. et al. Estudo da influência de variáveis de processo na produção de lipases por fungo filamentoso. In: SIMPÓSIO NACIONAL DE BIOPROCESSOS, 17, 2009 , Natal. Anais... Natal: Universidade Federal do Rio Grande do Norte, 2009. 6p.

MACEDO, G. A.; PASTORE, G. M. Lipases microbianas na produção de ésteres formadores de aroma. Ciência e Tecnologia de Alimentos, v. 17, n. 2, p. 115-119, 1997.

MALA, J. G. S. et al. Mixed substrate solid state fermentation for production and extraction of lipase from Aspergillus niger MTCC 2594. Journal of General and Applied Microbiology, v. 53, n. 4, p. 247-253, 2007.

MESSIAS, J. M. et. al. Lipases microbianas: produção, propriedades e aplicações biotecnológicas. Ciências Exatas e Tecnológicas, v. 32, n. 2, p. 213-234, 2011.

MURUCI, L. N. M. et al. Produção de lipase de Aspergillus niger utilizando co-produtos da indústria de refino de óleos. In:
CONGRESSO BRASILEIRO DE ENGENHARIA QUÍMICA, 19., 2012, Búzios, RJ. Anais... São Paulo: ABEQ, 2012. p. 12104-12112.

PALMA, M. et al. Lipase production by Penicilium restrictum using solid waste of industrial babassu oil production as substrate. Applied Biochemistry and Biotechnology, v. 8486 , p. $1137-1145,2000$

PEREIRA, E. B. et al. Kinetic studies of lipase from Candida rugosa: a comparative study between free and enzyme immobilized onto porous chitosan beads. Applied Biochemistry and Biotechnology, v. 91, p. 739-752, 2001.

REHMAN, S. et al. Optimization of process parameters for enhanced production of lipase by Penicillium notatum using agricultural wastes. African Journal of Biotechnology, v. 10, n. 84, p. 19580-19589, 2011.

SANTOS, R. R. et al. Characterization of different oil soapstocks and their application in the lipase production by Aspergillus niger under solid state fermentation. Journal of Food and Nutrition Research, v. 2, p. 561-566, 2014.

SCHUBER, L. C. L. et al. Isolamento e seleção de fungos produtores de $\beta$-galactosidase. Evidência, v. 12, n. 1, p. $19-40,2012$

SILVEIRA, C. M.; BADIALE-FURLONG, E. Caracterização de compostos nitrogenados presentes em farelos fermentados em estado sólido. Ciência e Tecnologia de Alimentos, v. 27, p. 805-811, 2007.

TOSCANO, L. et al. Production and partial characterization of extracellular lipase from Trichoderma harzianum by solid-state fermentation. Biotechnology \& Biotechnological Equipment, v. 27, n. 3, p. 3776-3781, 2013. 